\title{
The Effect of Bamboo Surface Roughness of Cutting Parameters on the Bamboo Milling
}

\author{
Yanhe Liu, ${ }^{\mathrm{a}, \mathrm{b}}$ Jianbo Zhou, ${ }^{\mathrm{a}, \mathrm{b}, *}$ Wansi Fu, ${ }^{\mathrm{b}}$ Bin Zhang, ${ }^{\mathrm{a}, \mathrm{b}}$ Feihu Chang, \\ and Pengfei Jiang a,b
}

\begin{abstract}
The surface roughness of bamboo is a factor that determines the processing quality. The effects of spindle speed, feed speed, and cutting depth on the surface roughness of bamboo were studied using the orthogonal design test method. The results were analyzed using range analysis, main effect analysis, interaction analysis, and variance analysis to determine the effect of cutting parameters on the surface roughness of bamboo. The feed speed had a greater effect on the surface roughness of the bamboo in the tangential section; the spindle speed had a greater impact on the surface roughness of the bamboo in the cross section. The cutting depth had a greater impact on the surface roughness of the bamboo in the radial section. For the surface roughness on the tangential, cross, and radial sections of the bamboo, there was a relationship with the cutting parameters. A mathematical model for the analysis of surface roughness was established by response surface method. Also, contour and surface plots based on regression models showed the correlation between surface roughness and all possible pairwise combinations of three cutting parameter variables. The cutting technology with the best surface quality was determined by optimization analysis.
\end{abstract}

Keywords: Bamboo; Orthogonal design; Spindle speed; Feed speed; Cutting depth; Mathematical model; Surface roughness

Contact information: a: Institute of New Forest Technology, Chinese Academy of Forestry, Beijing, China, 100091; b: Beijing Forestry Machinery Research Institute of State Forestry and Grassland Administration, Beijing, China, 100029; *Corresponding author: zhoujianbol@126.com

\section{INTRODUCTION}

As a renewable material with excellent properties, bamboo has high strength, hardness, stiffness, and a short production cycle. It is widely used in construction, furniture, food and other fields. It is a kind of "green" raw material that can replace wood.

Bamboo milling refers to the surface preparation procedure that occurs during the preliminary processing stage of bamboo. The preparation of the bamboo surface is done to achieve good processing surface quality, and as a bamboo milling performance evaluation standard, the product surface roughness is usually considered. Surface roughness has a significant effect on the processing quality and the aesthetics of bamboo products. Xiao et al. (2016) studied the effect of three cutting parameters of spindle speed, feed speed, and cutting depth on the surface roughness of AISI 1045 steel in the hard turning test of YT5 tool using the orthogonal experimental method, established are lative regression model and also optimized for the best cutting conditions. Sar1kaya and Güllü (2014) designed L16 $\left(4^{3}\right.$ $\times 2^{1}$ ) experiments based on Taguchi principles. The effect of different cutting parameters on the surface roughness of AISI 1050 steel during turning were studied. The experiments were carried out under the conditions of dry cutting (DC), conventional wet cooling, and 
MQL, respectively. The mathematical model of surface roughness was established and optimized using the response surface method. Çelik et al. (2016) used CVD and PVD coated carbide tools to turn Ti-6Al-4V alloy, and they studied the effect of different spindle speed, feed speed, cutting length and cutting depth on tool wear and surface roughness. Saini et al. (2012) studied the effect of cooling conditions, spindle speed, feed speed and cutting depth on tool wear and surface roughness when turning AISI H11 tool steel with ceramic tools. The response surface method was used to model and predict the surface roughness and tool wear at different cutting conditions.

Hanafi et al. (2012) employed the gray correlation theory and Taguchi optimization in tin tool cutting peek-cf30 to obtain the cutting parameter combination that achieved the lowest power and the best surface roughness while maintaining the machining quality of the workpiece and decreasing pollution of the environment at the same time. Yan and $\mathrm{Li}$ (2013) used weighted gray correlation analysis and response surface method to study the multi-objective optimization of the cutting parameters between energy, production efficiency, and cutting quality. They obtained the optimal surface roughness, material removal rate, and cutting energy consumption. They concluded that the traditional objective optimization method cannot meet the requirements of sustainable development of machining. Debnath et al. (2016) used Taguchi orthogonal test method to design a test scheme. $\mathrm{TiCN}+\mathrm{Al}_{2} \mathrm{O}_{3}+\mathrm{TiN}$ coated carbide tool was used to turn low carbon steel. The effects of the different cutting parameters and cutting fluid parameters on the surface roughness and tool wear were studied.

Artificial neural network is an algorithmic mathematical model which imitates the behavior characteristics of animal neural network and carries out distributed parallel information processing. It can better design experimental scheme and process experimental data. Tiryaki et al. (2016) investigated using artificial neural network to derive a mathematical model that is based on the data of the various processing parameters on the surface roughness of wood in abrasive machining process; it was found that the impact of power consumption determined the optimal cutting parameter value to minimize cost. Stanojevic et al. (2017) studied the influence of the feed speed, cutting depth, and front angle on surface roughness and power consumption by using the neural fuzzy method and represented it in a model. The results of this study can be applied in the wood industry to minimize energy consumption and experimental costs. Goli et al. (2018) proposed a novel experimental method to evaluate the specific cutting coefficient in the isotropic and orthotropic milling of wood materials and also to optimize and compare materials and processes.

Li et al. (2019) studied the cutting performance of micro-grain in wood cutting, the cutting force of turning, and how the surface friction coefficient between the front cutting surface and chip can be reduced. The energy consumption was reduced and the processing quality was improved. Kamboj et al. (2020) studied the effect of thermal modification on the surface quality and the cutting capability of eucalyptus wildebeest processing machines, and carried out edge milling at different cutting speeds, front angles, and feed speeds, to optimize and analyze the best surface quality and the amount of energy consumed. Using the single factor analysis method, Guo (2009) studied the effect of cutting tool rake angle, milling speed, milling depth, radial surface, and chord surface of longitudinal cutting on the milling performance of bamboo. Wu (2006) studied the effect of bamboo's physical properties and cutting parameters on the cutting quality using a highspeed camera and micro measurement technology, which achieved the purpose of reducing cost and improving quality. 
At present, a large number of researchers are engaged in metal cutting and wood cutting research, and few are engaged in bamboo cutting research, but the research on bamboo cutting is also very important. In this paper, the effect of cutting parameters (spindle speed, feed speed, and cutting depth) on the surface roughness of bamboo was studied using an orthogonal experiment. The mathematical model of the relationship between cutting parameters and the surface roughness of bamboo was established, and the cutting technology of the surface roughness of bamboo was optimized. Furthermore, the spindle speed, feed speed and cutting depth corresponding to the best cutting technology under the experimental conditions are determined.

\section{EXPERIMENTAL}

\section{Selection of Cutting Parameters and Their Levels}

This study was conducted in the SMART five-axis machining center established by Paolino Bacci in Italy. The experimental material was bamboo plywood, which is formed by a bamboo cross and side hot pressing, as shown in Fig. 1. The bamboo cross and side hot pressing test material length $\times$ width $\times$ height were $15 \mathrm{~cm} \times 15 \mathrm{~cm} \times 2 \mathrm{~cm}$. The workpiece of bamboo plywood was milled with a manganese plated carbide cutter. The view of the cut area layout is shown in Fig. 2. The bamboo material was milled with a 12T thin face milling cutter with 27 flat knives produced by Hangzhou Xiaoshan Baolifeng bamboo cutting tool factory (Hangzhou, China). The effect of three cutting parametersspindle speed, feed speed, and cutting depth - on the surface roughness of bamboo was considered. The cutting parameters and their levels are shown in Table 1.

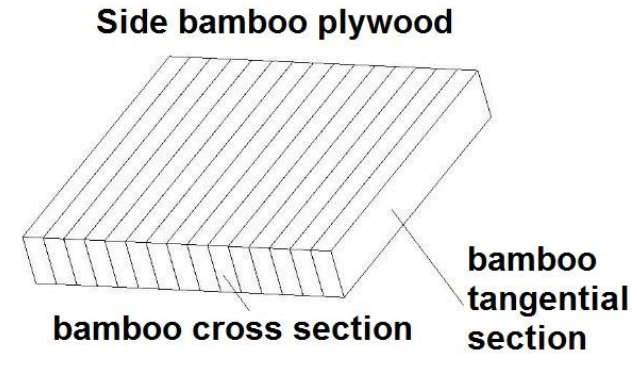

(a) Side bamboo plywood

Fig. 1. Bamboo plywood work piece

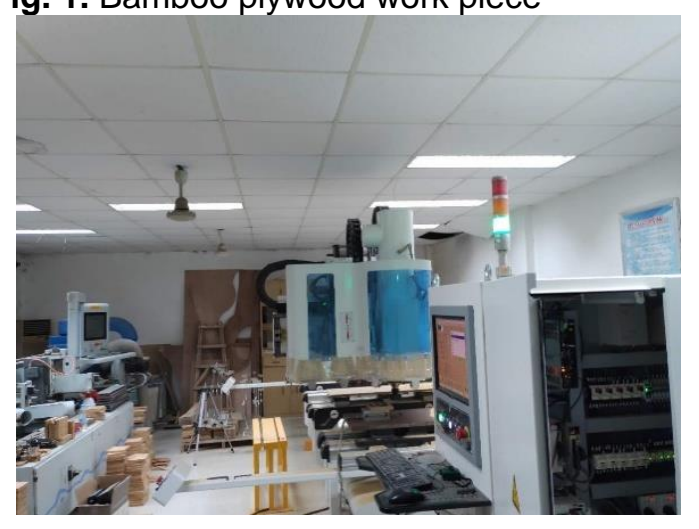

Fig. 2. SMART five-axis machining center

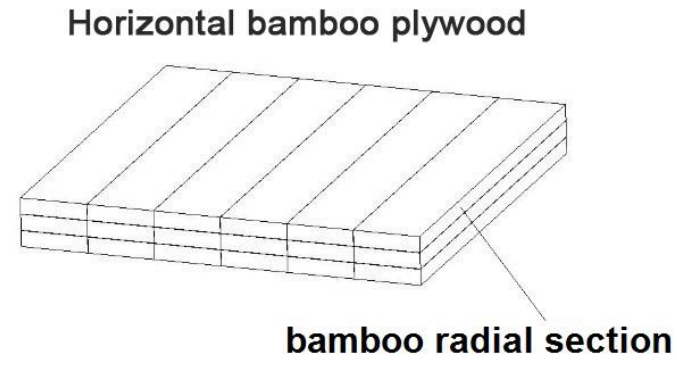

(b) Horizontal bamboo plywood

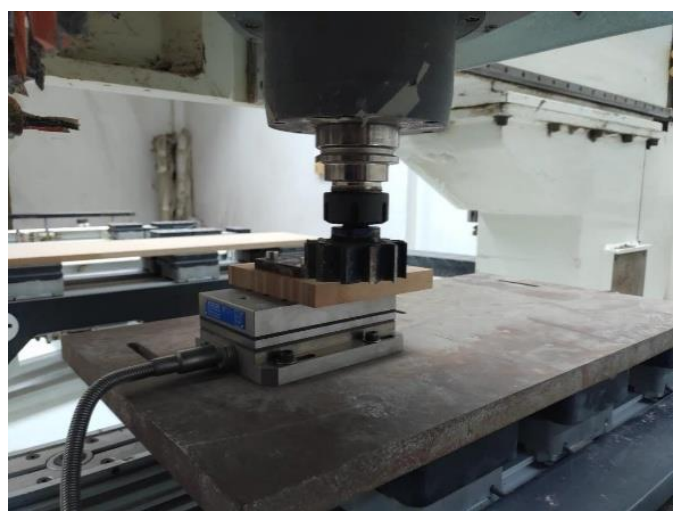


The contact-type measuring instrument S-NEX001SD-12 (Olympus, Co. Ltd., Japan) was used to measure the surface roughness and measurement at three different locations reduces the error. The average values of $R_{\mathrm{a}}$ (arithmetic average of absolute values of roughness profile) were considered for analysis. $R_{\text {a }}$ was used to measure the variables: the strings, the end face, and the diameter of the bamboo workpiece. An average value of the surface roughness was calculated in five sets each for the tangential section surface roughness of the bamboo, $R_{\mathrm{a}} 1$, the cross-section surface roughness of the bamboo, $R_{\mathrm{a}} 2$, and the radial surface roughness, $R_{\mathrm{a}} 3$. The cut-off length and sampling number of surface roughness measurement are $1 \mathrm{~mm}$ and 5 times respectively.

Table 1. Processing Parameters and Levels

\begin{tabular}{|c|c|c|c|}
\hline & Symbol & Level & Code \\
\hline \multirow{3}{*}{ Spindle speed $(\mathrm{rpm})$} & $\mathrm{n} 1$ & 3500 & 1 \\
\cline { 2 - 4 } & $\mathrm{n} 2$ & 4000 & 2 \\
\cline { 2 - 4 } & $\mathrm{n} 3$ & 4500 & 3 \\
\hline \multirow{3}{*}{ Feed rate $(\mathrm{m} / \mathrm{min})$} & $\mathrm{f} 1$ & 5 & 2 \\
\cline { 2 - 4 } & $\mathrm{f} 2$ & 10 & 3 \\
\hline \multirow{3}{*}{ Cutting depth $(\mathrm{mm})$} & $\mathrm{f} 3$ & 15 & 1 \\
\cline { 2 - 4 } & $\mathrm{d} 1$ & 1 & 3 \\
\cline { 2 - 4 } & $\mathrm{d} 2$ & 2 & 3 \\
\hline
\end{tabular}

\section{Experimental Design}

In this experiment, there were 3 parameter variables. Each parameter level was 3, and the number of normal experiments was $3^{*} 3^{3}=81$ (each group of experiments was repeated three times). To reduce the number of experiments and ensure adequate information, orthogonal experiments were used to design the experimental scheme (Xiao et al. 2016). In this study, 4 columns and 9 rows of L9 orthogonal tables were selected, and 9 parameter combinations were available. Therefore, the design experiment of the L9 orthogonal array only needed $9 * 3=27$ times. As shown in Table 2 , a column array is empty for the experimental error, which does not affect orthogonality.

Table 2. L9 Orthogonal Experiment Table

\begin{tabular}{|c|c|c|c|c|}
\hline \multirow{2}{*}{ Experiment number } & \multicolumn{4}{|c|}{ Cutting parameter level } \\
\cline { 2 - 5 } & $\begin{array}{c}n \\
\text { Spindle speed } \\
(\mathrm{rpm})\end{array}$ & $\begin{array}{c}f \\
\text { Feed rate } \\
(\mathrm{m} / \mathrm{min})\end{array}$ & $\begin{array}{c}d \\
\text { Cutting depth } \\
(\mathrm{mm})\end{array}$ & error \\
\hline 1 & 1 & 1 & 1 & \\
\hline 2 & 1 & 2 & 2 & \\
\hline 3 & 1 & 3 & 3 & \\
\hline 4 & 2 & 1 & 2 & \\
\hline 5 & 2 & 2 & 3 & \\
\hline 6 & 2 & 3 & 1 & \\
\hline 7 & 3 & 2 & 3 & \\
\hline 8 & 3 & 3 & 1 & \\
\hline 9 & 3 & & 2 & \\
\hline
\end{tabular}




\section{RESULTS AND DISCUSSION}

The orthogonal test results of the surface roughness are shown in Table 3. The range analysis, main effect analysis, range analysis, interaction analysis, variance analysis, and mathematical modeling analysis were conducted.

Table 3. Surface Roughness Test Results

\begin{tabular}{|c|c|c|c|c|c|c|}
\hline $\begin{array}{c}\text { Experiment } \\
\text { number }\end{array}$ & $\begin{array}{c}\text { Spindle } \\
\text { speed } \\
(\mathrm{rpm})\end{array}$ & $\begin{array}{c}\text { Feed rate } \\
(\mathrm{m} / \mathrm{min})\end{array}$ & $\begin{array}{c}\text { Cutting } \\
\text { depth } \\
(\mathrm{mm})\end{array}$ & $\begin{array}{c}R_{\mathrm{a}} 1 \\
(\mu \mathrm{m})\end{array}$ & $\begin{array}{c}R_{\mathrm{a}} 2 \\
(\mu \mathrm{m})\end{array}$ & $\begin{array}{c}R_{\mathrm{a}} 3 \\
(\mu \mathrm{m})\end{array}$ \\
\hline 1 & 3500 & 5 & 1 & 1.66 & 5.03 & 2.2 \\
\hline 2 & 3500 & 10 & 1.5 & 2.94 & 5.18 & 2.11 \\
\hline 3 & 3500 & 15 & 2 & 2.47 & 6.36 & 2.21 \\
\hline 4 & 4000 & 5 & 1.5 & 1.67 & 3.94 & 1.97 \\
\hline 5 & 4000 & 10 & 2 & 2.57 & 4.31 & 2.06 \\
\hline 6 & 4000 & 15 & 1 & 2.29 & 5.15 & 2.31 \\
\hline 7 & 4500 & 5 & 2 & 1.84 & 4.07 & 2.05 \\
\hline 8 & 4500 & 10 & 1 & 2.39 & 5.24 & 2.5 \\
\hline 9 & 4500 & 15 & 1.5 & 2.28 & 3.94 & 2.22 \\
\hline
\end{tabular}

\section{Range Analysis}

The effect of each cutting parameter on the surface roughness of bamboo can be separated at the different levels of the cutting parameters. The average surface roughness of experiment numbers 1-3, 4-6, and 7-9 were used as the average roughness of the spindle speed at levels 1, 2, and 3. Similarly, the average roughness of each level of other cutting parameters was calculated, as listed in Table 4. In the analysis table of average roughness range, the total average surface roughness of the tangential, cross, and radial sections of the bamboo was calculated.

Table 4. Range Analysis

\begin{tabular}{|c|c|c|c|c|c|}
\hline \multirow{2}{*}{ Symbol } & \multirow{2}{*}{ parameter } & \multicolumn{4}{|c|}{ Bamboo tangential section surface roughness: $R_{\mathrm{a}} 1$} \\
\cline { 3 - 6 } & & Level 1 & Level 2 & Level 3 & range \\
\hline $\mathrm{n}$ & Spindle speed & 2.357 & 2.177 & 2.170 & 0.187 \\
\hline $\mathrm{f}$ & Feed rate & 1.723 & 2.633 & 2.347 & 0.910 \\
\hline $\mathrm{d}$ & Cutting depth & 2.113 & 2.297 & 2.293 & 0.184 \\
\hline \multirow{2}{*}{ Symbol } & \multirow{2}{*}{ parameter } & \multicolumn{2}{|c|}{ Bamboo cross section surface roughness: $R_{\mathrm{a}} 2$} \\
\cline { 3 - 6 } & & Level 1 & Level 2 & Level 3 & range \\
\hline $\mathrm{n}$ & Spindle speed & 5.523 & 4.467 & 4.417 & 1.106 \\
\hline $\mathrm{f}$ & Feed rate & 4.347 & 4.910 & 5.150 & 0.803 \\
\hline $\mathrm{d}$ & Cutting depth & 5.140 & 4.353 & 4.913 & 0.787 \\
\hline \multirow{2}{*}{ Symbol } & \multirow{2}{*}{ parameter } & \multicolumn{2}{|c|}{ Bamboo radial section surface roughness: Ra3 } \\
\cline { 3 - 6 } & & Level 1 & Level 2 & Level 3 & range \\
\hline $\mathrm{n}$ & Spindle speed & 2.173 & 2.113 & 2.257 & 0.144 \\
\hline $\mathrm{f}$ & Feed rate & 2.073 & 2.223 & 2.247 & 0.174 \\
\hline $\mathrm{d}$ & Cutting depth & 2.337 & 2.100 & 2.107 & 0.237 \\
\hline
\end{tabular}

Total average of Ra1: $2.234 \mu \mathrm{m}$, Standard deviation of Ra1:0.244 $\mu \mathrm{m}$;

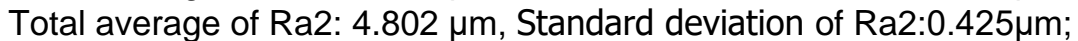

Total average of Ra3: $2.181 \mu \mathrm{m}$, Standard deviation of Ra3:0.090 $\mu \mathrm{m}$.

According to the analysis results, the feed speed had the most significant effect on $R_{\mathrm{a}} 1$. Among the three factors, the effect of spindle speed on $R_{\mathrm{a}} 1$ was the second, and the 
cutting depth was the least. The effect of spindle speed on $R_{\mathrm{a}} 2$ was the most significant followed by the feed speed of $R_{\mathrm{a}} 2$, and then cutting depth. The cutting depth had the most significant effect on $R_{\mathrm{a}} 3$, followed by the feed speed, and the spindle speed was the least significant factor. Based on the growth characteristics of bamboo, the surface roughness of the string surface and diameter surface of bamboo was generally lower than that of the end surface. The total average surface roughness of $R_{\mathrm{a}} 1$ was $2.234 \mu \mathrm{m}$, for $R_{\mathrm{a}} 2$ it was 4.802 $\mu \mathrm{m}$, and for $R_{\mathrm{a}} 3$ it was $2.181 \mu \mathrm{m}$. The standard deviation surface roughness of $R_{\mathrm{a}} 1$ was $0.244 \mu \mathrm{m}$, for $R_{\mathrm{a}} 2$ it was $0.425 \mu \mathrm{m}$, and for $R_{\mathrm{a}} 3$ it was $0.090 \mu \mathrm{m}$.

\section{Main Effect Analysis}

The effect of surface roughness of bamboo is shown in Fig. 3. Generally, the better surface machining quality ( $R_{\mathrm{a}}$ minimum) generally appears at the higher spindle speed, lower feed rate, and lower cutting depth. With the increase of spindle speed, the cutting amount per unit time increases, which improves the machining accuracy and surface quality. However, if the spindle speed is too high, the tool wear will be accelerated and the surface quality will be reduced. With the increase of feed rate, the machining amount per revolution of tool increases; that is to say, the amount of material cut from the workpiece by the tool per revolution becomes larger, which will reduce the surface quality, but the low feed rate will significantly affect the processing efficiency. Cutting depth and feed rate have similar effects on surface quality and machining efficiency. As shown in Fig. 3 (a), the feed speed highly affected $R_{\mathrm{a}} 1$. When the feed speed was increased from $5 \mathrm{~m} / \mathrm{min}$ to 10 $\mathrm{m} / \mathrm{min}$, the surface roughness showed an upward trend, but when the feed speed was greater than $10 \mathrm{~m} / \mathrm{min}$, the surface roughness decreased slightly with the increase of the feed speed.

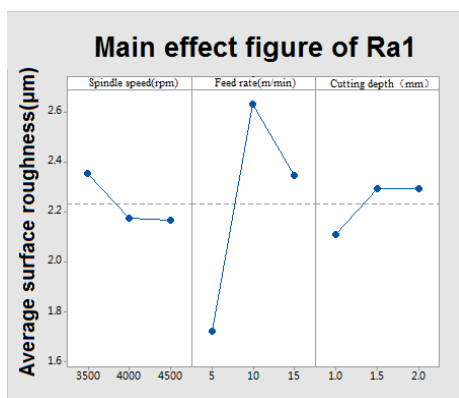

(a) Main effect figure of $R_{a} 1$

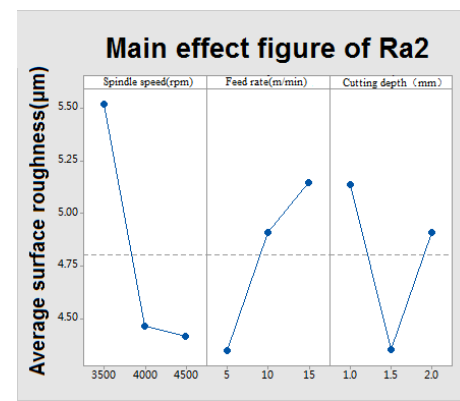

(b) Main effect figure of $R_{a} 2$

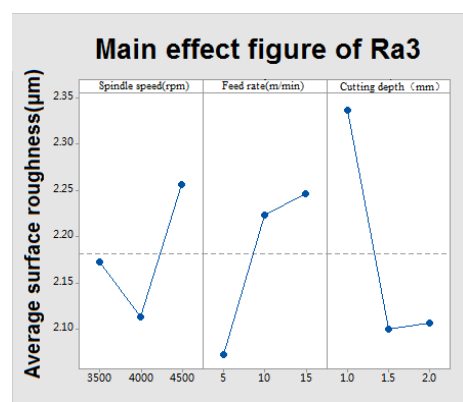

(c) Main effect figure of $R_{a} 3$

Fig. 3. Main effect figure of average surface roughness $R_{a}$

As shown in Fig. 3 (a), the highest surface roughness occurred at a feed speed of $10 \mathrm{~m} / \mathrm{min}$, and the lowest surface roughness occurred when the feed speed was at $5 \mathrm{~m} / \mathrm{min}$, that is, at the best surface quality. With an increase in spindle speed, the surface roughness value decreased. The highest surface roughness occurred at a spindle speed of $3500 \mathrm{rpm}$, and the lowest surface roughness occurred at a spindle speed of $4500 \mathrm{rpm}$. As the cutting depth increased from $1.0 \mathrm{~mm}$ to $1.5 \mathrm{~mm}$, the surface roughness increased rapidly. The highest surface roughness occurred at a cutting depth of $1.0 \mathrm{~mm}$, and the lowest surface roughness was at a cutting depth of $1.5 \mathrm{~mm}$, which was the best surface quality. When the cutting depth was increased from $1.5 \mathrm{~mm}$ to $2.0 \mathrm{~mm}$, the surface roughness decreased slightly. These results suggested that the combination of the cutting parameters for the best surface roughness of $R_{\mathrm{a}} 1$ was the level-3 spindle speed, level-1 feed speed, and level-1 cutting depth. 
As shown in Fig. 3 (b), the spindle speed had a strong influence on the surface roughness of the bamboo cross-section. The surface roughness decreased as the spindle speed increased from $3500 \mathrm{rpm}$ to $4000 \mathrm{rpm}$. When the spindle speed was greater than $4000 \mathrm{rpm}$, the surface roughness increased rapidly with the increase of the spindle speed. The highest surface roughness occurred at a spindle speed of $4500 \mathrm{rpm}$, and the lowest surface roughness occurred at a spindle speed of $4000 \mathrm{rpm}$, which was the best surface quality. With an increase in feed speed, the surface roughness value showed an upward trend. The highest surface roughness occurred at a feed speed of $15 \mathrm{~m} / \mathrm{min}$, and the lowest surface roughness occurred at a feed speed of $5 \mathrm{~m} / \mathrm{min}$. When the cutting depth increased from $1.0 \mathrm{~mm}$ to $1.5 \mathrm{~mm}$, the surface roughness decreased rapidly, and when the cutting depth increased from $1.5 \mathrm{~mm}$ to $2.0 \mathrm{~mm}$, the surface roughness increased slightly. The highest surface roughness occurred when the cutting depth was $1 \mathrm{~mm}$, and the lowest surface roughness occurred when the cutting depth was $1.5 \mathrm{~mm}$, which implies the best surface quality. From the above analysis, it was concluded that the combination of the cutting parameters for the best surface roughness of $R_{\mathrm{a}} 2$ was the level- 3 spindle speed, the level-1 feed speed, and the level-1 cutting depth.

As shown in Fig. 3 (c), the cutting depth strongly affected $R_{\mathrm{a}} 3$. When the cutting depth increased from $1.0 \mathrm{~mm}$ to $1.5 \mathrm{~mm}$, the surface roughness decreased rapidly, and when the cutting depth increased from $1.5 \mathrm{~mm}$ to $2.0 \mathrm{~mm}$, the surface roughness increased slightly. The highest surface roughness occurred when the cutting depth was $1 \mathrm{~mm}$, and the lowest surface roughness occurred when the cutting depth was $1.5 \mathrm{~mm}$, which was the best surface quality. With the increase in feed speed, the surface roughness value showed an upward trend. The highest surface roughness occurred at a feed speed of $15 \mathrm{~m} / \mathrm{min}$, and the lowest surface roughness occurred at a feed speed of $5 \mathrm{~m} / \mathrm{min}$. The surface roughness decreased when the spindle speed increased from $3500 \mathrm{rpm}$ to $4000 \mathrm{rpm}$. When the spindle speed was greater than $4000 \mathrm{rpm}$, the surface roughness increased rapidly with the increase in the spindle speed. The highest surface roughness occurred at a spindle speed of 4500 $\mathrm{rpm}$, and the lowest surface roughness at a spindle speed of $4000 \mathrm{rpm}$, which was the best surface quality. According to the above analysis, it was concluded that the cutting parameters of level-2 spindle speed, level-1 feed speed, and level-2 cutting depth are the best combination of the surface roughness of $R_{\mathrm{a}} 3$.

\section{Variance Analysis}

The effect of spindle speed, feed speed and cutting depth on the bamboo surface roughness was analyzed using variance analysis to determine the significance level of each variable. The analysis of variance of the test results of the surface roughness of bamboo $\left(R_{\mathrm{a}} 1, R_{\mathrm{a}} 2\right.$, and $\left.R_{\mathrm{a}} 3\right)$ is shown in Table 6 .

Through the evaluation of $R_{\mathrm{a}} 1$, it was found that the variable that had the greatest effect on the $R_{\mathrm{a}} 1$ value was the feed speed with a contribution rate of $45.39 \%$. Other variables affecting $R_{\mathrm{a}} 1$ were spindle speed and cutting depth, with contribution rates of $2.34 \%$ and $2.31 \%$, respectively, and with errors of $49.965 \%$ (Table 6 ). The feeding speed (factor $\mathrm{B}$ ) was the factor that mostly affects $R_{\mathrm{a}} 1$. The influence of spindle speed (factor $\mathrm{A}$ ) and cutting depth (factor $\mathrm{C}$ ) on $R_{\mathrm{a}} 1$ was not significant in the given range. 
Table 6. Surface Roughness Variance Analysis

\begin{tabular}{|c|c|c|c|c|c|c|}
\hline Symbol & parameter & DOF & SS & $\mathrm{F}$ & $\begin{array}{l}\text { Mean } \\
\text { square }\end{array}$ & $\begin{array}{c}\text { Contribution } \\
(\%)\end{array}$ \\
\hline \multicolumn{7}{|c|}{ Bamboo tangential section surface roughness (Ra1) } \\
\hline $\mathrm{n}$ & Spindle speed & 2 & 0.067 & 0.14 & 0.034 & 2.341 \\
\hline$f$ & Feed rate & 2 & 1.299 & 2.721 & 0.650 & 45.388 \\
\hline$d$ & Cutting depth & 2 & 0.066 & 0.138 & 0.033 & 2.306 \\
\hline Error & & 6 & 1.43 & & 0.238 & 49.965 \\
\hline Total & & 12 & 2.862 & & & 100 \\
\hline \multicolumn{7}{|c|}{ Bamboo cross section surface roughness (Ra2) } \\
\hline $\mathrm{n}$ & Spindle speed & 2 & 2.344 & 1.617 & 1.172 & 26.949 \\
\hline$f$ & Feed rate & 2 & 1.02 & 0.704 & 0.510 & 11.727 \\
\hline$d$ & Cutting depth & 2 & 0.984 & 0.679 & 0.492 & 11.313 \\
\hline Error & & 6 & 4.35 & & 0.725 & 50.011 \\
\hline Total & & 12 & 8.698 & & & 100 \\
\hline \multicolumn{7}{|c|}{ Bamboo radial section surface roughness (Ra3) } \\
\hline $\mathrm{n}$ & Spindle speed & 2 & 0.031 & 0.482 & 0.016 & 8.094 \\
\hline$f$ & Feed rate & 2 & 0.053 & 0.824 & 0.027 & 13.838 \\
\hline$d$ & Cutting depth & 2 & 0.109 & 1.694 & 0.055 & 28.460 \\
\hline Error & & 6 & 0.19 & & 0.032 & 49.608 \\
\hline Total & & 12 & 0.383 & & & 100 \\
\hline
\end{tabular}

Through the evaluation of $R_{\mathrm{a}} 2$, it was found that the variable that had the greatest influence on the value of $R_{\mathrm{a}} 2$ was the spindle speed with the contribution rate of $26.95 \%$. The contribution rates of the feed speed and the cutting depth of $R_{\mathrm{a}} 2$ were $11.73 \%$ and $11.31 \%$, respectively, and with an error of $50.01 \%$ (Table 6). The spindle speed (factor A) is the factor that mostly affects $R_{\mathrm{a}} 2$. The effects of the feed speed (factor $\mathrm{B}$ ) and the cutting depth (factor $\mathrm{C}$ ) on the $R_{\mathrm{a}} 2$ were significant and comparable in the given range.

Through the evaluation of the surface roughness $R_{\mathrm{a}} 3$, it was determined that the cutting depth had a contribution rate of $28.46 \%$ and had the greatest effect on the value of $R_{\mathrm{a}} 3$. It was found that the contribution rates of spindle speed and feed speed of $R_{\mathrm{a}} 3$ are $8.09 \%$ and $13.84 \%$, respectively, with an error of $49.61 \%$ (Table 6). The cutting depth (factor $\mathrm{C}$ ) is the factor that most affected $R_{\mathrm{a}} 3$. The feeding speed (factor $\mathrm{B}$ ) had a significant effect on $R_{\mathrm{a}} 3$ in a given range. The effect of spindle speed (factor $\mathrm{A}$ ) on $R_{\mathrm{a}} 3$ was not significant within the given range.

\section{Interaction Analysis}

The results of the interactive effect on the surface roughness of the tangential, cross, and radial sections of bamboo are shown in Table 5. The interaction effect diagram is 
shown in Fig. 4. Each interaction effect diagram shows the interaction diagram of the combination of two cutting parameters.

Table 5. Surface Roughness Interaction Effect

\begin{tabular}{|c|c|c|c|c|c|c|c|c|c|}
\hline & \multicolumn{3}{|c|}{$R_{\mathrm{a}} 1$} & \multicolumn{3}{|c|}{$R_{\mathrm{a}} 2$} & \multicolumn{3}{|c|}{$R_{a} 3$} \\
\hline $\begin{array}{l}\text { Feed } \\
\text { rate }\end{array}$ & \multicolumn{3}{|c|}{ Spindle speed (rpm) } & \multicolumn{3}{|c|}{ Spindle speed (rpm) } & \multicolumn{3}{|c|}{ Spindle speed (rpm) } \\
\hline & 3500 & 4000 & 4500 & 3500 & 4000 & 4500 & 3500 & 4000 & 4500 \\
\hline 5 & 1.66 & 2.39 & 2.29 & 5.03 & 5.24 & 5.15 & 2.2 & 2.5 & 2.31 \\
\hline 10 & 1.67 & 2.94 & 2.28 & 3.94 & 5.18 & 3.94 & 1.97 & 2.11 & 2.22 \\
\hline 15 & 1.84 & 2.57 & 2.47 & 4.07 & 4.31 & 6.36 & 2.05 & 2.06 & 2.21 \\
\hline $\begin{array}{l}\text { Cutting } \\
\text { depth } \\
(\mathrm{mm})\end{array}$ & \multicolumn{3}{|c|}{ Spindle speed (rpm) } & \multicolumn{3}{|c|}{ Spindle speed (rpm) } & \multicolumn{3}{|c|}{ Spindle speed (rpm) } \\
\hline & 3500 & 4000 & 4500 & 3500 & 4000 & 4500 & 3500 & 4000 & 4500 \\
\hline 1 & 1.66 & 2.57 & 2.28 & 5.03 & 4.31 & 3.94 & 2.2 & 2.06 & 2.22 \\
\hline 1.5 & 1.84 & 2.94 & 2.29 & 4.07 & 5.18 & 5.15 & 2.05 & 2.11 & 2.31 \\
\hline 2 & 1.67 & 2.39 & 2.47 & 3.94 & 5.24 & 6.36 & 1.97 & 2.5 & 2.21 \\
\hline $\begin{array}{l}\text { Cutting } \\
\text { depth } \\
(\mathrm{mm})\end{array}$ & \multicolumn{3}{|c|}{ Feed rate $(\mathrm{m} / \mathrm{min})$} & \multicolumn{3}{|c|}{ Feed rate $(\mathrm{m} / \mathrm{min})$} & \multicolumn{3}{|c|}{ Feed rate $(\mathrm{m} / \mathrm{min})$} \\
\hline & 5 & 10 & 15 & 5 & 10 & 15 & 5 & 10 & 15 \\
\hline 1 & 1.66 & 2.28 & 2.57 & 5.03 & 3.94 & 4.31 & 2.2 & 2.22 & 2.06 \\
\hline 1.5 & 2.29 & 2.94 & 1.84 & 5.15 & 5.18 & 4.07 & 2.31 & 2.11 & 2.05 \\
\hline 2 & 2.39 & 1.67 & 2.47 & 5.24 & 3.94 & 6.36 & 2.5 & 1.97 & 2.21 \\
\hline
\end{tabular}

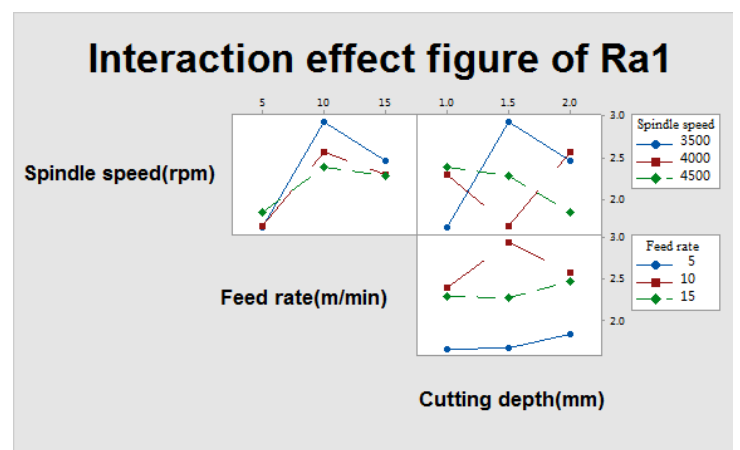

(a) Interaction effect figure of $R_{a} 1$

\section{Interaction effect figure of Ra3}

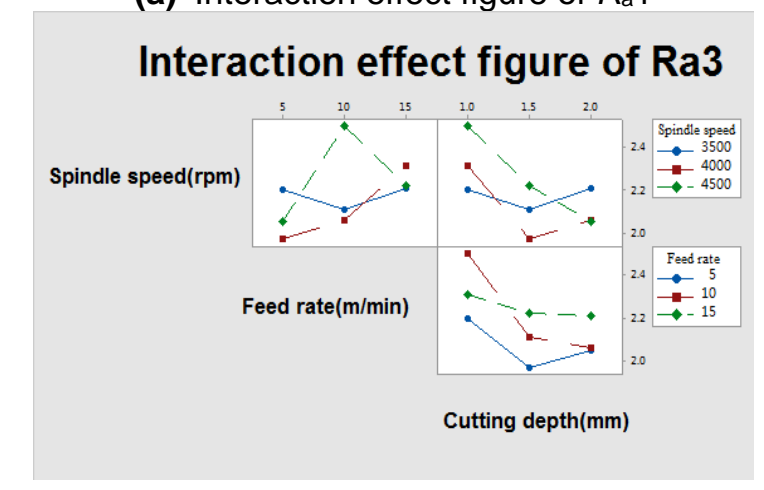

(c) Interaction effect figure of $R_{\mathrm{a}} 3$

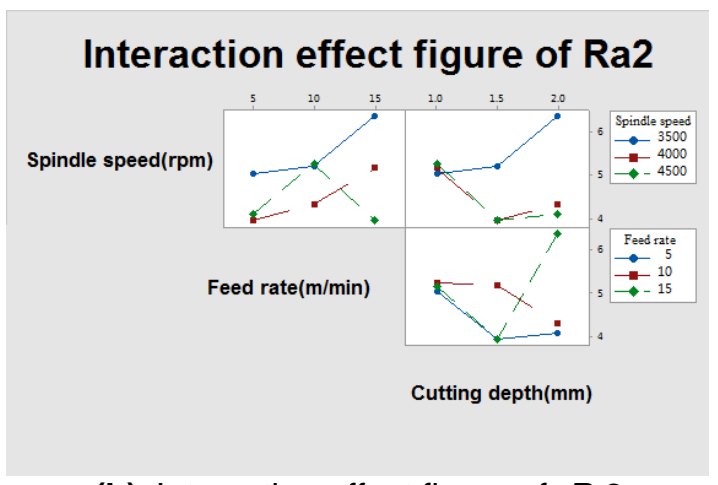

(b) Interaction effect figure of $R_{\mathrm{a}} 2$

Fig. 4. Interaction effect figure of average surface roughness $R_{\mathrm{a}}$ 
In Fig. 4 (a), the top row of the two pictures from left to right shows the three spindle speeds ( $3500 \mathrm{rpm}, 4000 \mathrm{rpm}, 4500 \mathrm{rpm}$ ), the average surface roughness, the feed rate, and cutting depth of interaction diagram. The second line graph shows the three feed speed $(5 \mathrm{~m} / \mathrm{min}, 10 \mathrm{~m} / \mathrm{min}, 15 \mathrm{~m} / \mathrm{min})$ from the average $R_{\mathrm{a}} 1$ and the cutting depth of the interaction diagram. All three interaction diagrams show non-parallel lines, indicating an interaction between cutting parameters. Similarly, all interaction diagrams in Fig. 4 (b) and (c) show non-parallel lines, indicating that there is also an interaction between cutting parameters.

\section{Mathematical Modeling and Analysis}

The response surface method was used to model and analyze the experiment, and the mathematical model of the bamboo milling process was established by the same method. MINITAB 17.0 software was used for calculations. To study the effect of cutting parameters on surface roughness, the regression equations of $R_{\mathrm{a}} 1, R_{\mathrm{a}} 2$, and $R_{\mathrm{a}} 3$ were derived according to the test data, as follows,

$$
y=\alpha_{1}+\alpha_{2} * x_{1}+\alpha_{3} * x_{2}+\alpha_{4} * x_{3}
$$

where $y$ represents the surface roughness, $x_{1}, x_{2}$, and $x_{3}$ refer to the cutting parameters. The term refers to the regression coefficient. The first-order model can be expressed as a function of the cooling conditions associated with the cutting parameters (spindle speed, feed speed, and cutting depth) and surface roughness $R_{\mathrm{a}}$. The relationship between surface roughness $R_{\mathrm{a}}$ and milling parameters is shown in Eq. 2.

$$
y=\alpha_{1}+\alpha_{2} * n+\alpha_{3} * f+\alpha_{4} * d
$$

The mathematical model between surface roughness $R_{\mathrm{a}}$ and milling parameters was established by replacing the numerical value in Eq. 2 with the experimental results, and the surface roughness $R_{\text {a }}$ model is obtained below.

$$
\begin{aligned}
& R_{\mathrm{a}} 1=2.09-0.000187 * n+0.0623 * f+0.18 * d \\
& R_{\mathrm{a}} 2=8.77-0.001107 * n+0.0803 * f-0.227 * d \\
& R_{\mathrm{a} 3}=2.019+0.000083 * n+0.01733 * f-0.23 * d
\end{aligned}
$$

The measurement coefficient $\mathrm{R}^{2}$ is a measure of the change in the mean value of the model's interpretation. For $R_{\mathrm{a}} 1, R_{\mathrm{a}} 2$, and $R_{\mathrm{a}} 3$, the $\mathrm{R}^{2}$ values were $45.60 \%, 55.43 \%$, and $66.59 \%$, respectively.

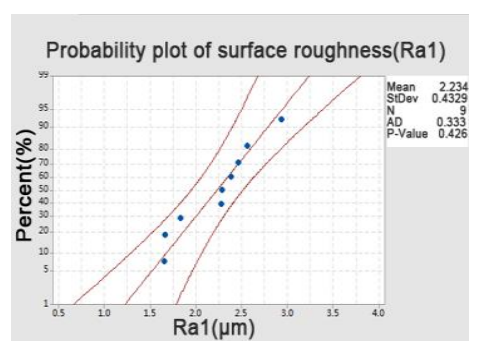

(a) Probability figure of $R_{\mathrm{a}} 1$

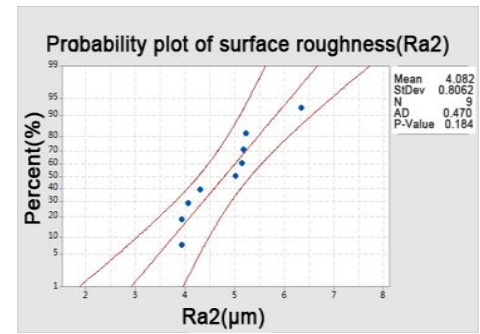

(b) Probability figure of $R_{a} 2$

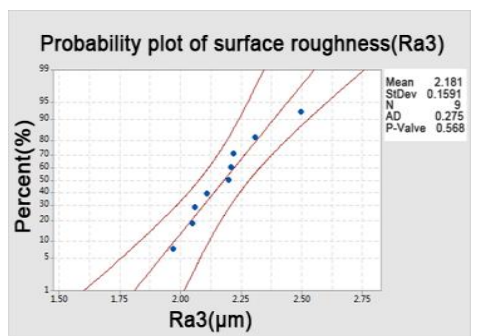

(c) Probability figure of $R_{\mathrm{a}} 3$

Fig. 5. Probability figure of surface roughness

Figure 5 shows the probability graph of surface roughness. In Fig. 5(a), the probability line explains that the surface roughness value of almost $70 \%$ of the bamboo's 
tangential section was lower than $2.5 \mu \mathrm{m}$, the average surface roughness of the bamboo's tangential section was $2.234 \mu \mathrm{m}$, and with a standard deviation of 0.4329 . Because the data points were roughly along a straight line, the $\mathrm{P}$-value was greater than 0.05 , and the $\mathrm{AD}$ statistical value was low. Therefore, it can be inferred that the data were from a normal distribution. Figures 5(b) and 5(c) have similar rules with Fig. 5(a), and $R_{\mathrm{a}} 1, R_{\mathrm{a}} 2$, and $R_{\mathrm{a}} 3$ data obtained from a normal distribution.

Because the data of $R_{\mathrm{a}} 1, R_{\mathrm{a}} 2$, and $R_{\mathrm{a}} 3$ were all from the normal distribution, the response surface of the second-order model can be fitted as Eq. 6,

$$
y=\alpha_{1}+\alpha_{2} * x_{1}+\alpha_{3} * x_{2}+\alpha \alpha_{4}^{*} x_{3}+\alpha_{5} * x_{1}{ }^{2}+\alpha{ }_{6}^{*} x_{2}{ }^{2}+\alpha_{7} * x_{3}{ }^{2}+\alpha x^{*} x_{1} * x_{2}+\alpha_{9} * x_{1} * x_{3}+\alpha_{10} * x_{2} * x_{3}
$$

where $y$ represents the surface roughness, $x_{1}, x_{2}$, and $x_{3}$ refer to the cutting parameters, and the regression coefficient refers to the parameter. The second-order model can be expressed as a function of the cooling conditions associated with the cutting parameters (spindle speed, feed speed, and cutting depth) and surface roughness $R_{\mathrm{a}}$. Since $f^{*} d$ cannot be estimated, it is deleted. The relationship between surface roughness $R_{\mathrm{a}}$ and cutting parameters is shown in Eq. 7.

$$
y=\alpha_{1}+\alpha_{2} * n+\alpha_{3} * f+\alpha_{4} * d+\alpha 5^{*} n^{2}+\alpha_{6} * f^{2}+\alpha_{7} * d^{2}+\alpha_{8} * n^{*} f+\alpha_{9} * n^{*} d
$$

The mathematical model between the surface roughness, $R_{\mathrm{a}}$ and the cutting parameters is established by replacing the numerical value in Eq. 7 with the experimental results, as shown below.

$$
\begin{aligned}
& R_{\mathrm{a}} 1=5.16-0.003293 * n+0.9297 * f-0.6467 * d+3.4667 * 10^{-7} * n^{2} \\
& \quad-0.02753 * f^{2}-0.7467 * d^{2}-7.467 * 10^{-5} * n^{*} f+0.00072 * n^{*} d ; \\
& R_{\mathrm{a}} 2=30.64-0.01344 * n+0.617 * f-0.36 * d+2.013 * 10^{-6} * n^{2} \\
& +0.001133 * f^{2}+1.9467 d^{2}-0.000149 * n^{*} f-0.00152 * n^{*} d ; \\
& R_{\mathrm{a}} 3=7.83-0.002763 * n+0.02767 * f-0.5867 * d+4.0667 * 10^{-7} * n^{2} \\
& -0.001133 * f^{2}+0.4933 * d^{2}+1.333 * 10^{-6 *} n^{*} f-0.00028 * n * d
\end{aligned}
$$

Because the degree of freedom of the error column is 0 , the values of feed speed and cutting depth cannot be calculated. One or more interaction terms will be deleted and the model will be fitted again. According to Eq. 8, the absolute value of the interaction term coefficient, $n^{*} f$ is $7.467 * 10^{-5}$, which is less than the absolute value of the interaction term coefficient, $n^{*} d$ which is 0.00072 . Therefore, the $n^{*} f$ term is deleted and the $R_{\mathrm{a}} 1$ model is fitted again. According to Eq. 9, the absolute value of the interaction term coefficient, $n^{*} f$ is 0.000149 , which is less than the absolute value of the interaction term coefficient, $n^{*} d$ which is 0.00152 . Therefore, the $n^{*} f$ term is deleted and the $R_{\mathrm{a}} 2$ model is fitted again. According to Eq. 10, the absolute value of the interaction term coefficient, $n^{*} f$ is $1.333^{*} 10^{-6}$, which is less than the absolute value of the interaction term coefficient, $n^{*} d$ that is 0.00028 . Thus, the $n^{*} f$ is deleted and the $R_{\mathrm{a}} 3$ model is fitted again. The modified model is as shown below.

$$
\begin{aligned}
& R_{\mathrm{a}} 1=6.653-0.00348 * n+0.584333 * f-0.0867 * d+3.467 * 10^{-7} * n^{2} \\
& -0.02567 * f^{2}-0.3733 * d^{2}+0.0003467 * n * d \\
& R_{\mathrm{a}} 2=33.6267-0.0138133 * n-0.07367 * f+0.76 * d+2.0133 * 10^{-6} * n^{2}
\end{aligned}
$$




$$
\begin{aligned}
& +0.004867 * f^{2}+2.6933 * d^{2}-0.002267 * n * d \\
& R_{\mathrm{a}} 3=7.803-0.00276 * n+0.03383 * f-0.5967 * d+4.067 * 10^{-7} * n^{2} \\
& -0.001167 * f^{2}+0.4867 * d^{2}-0.000273 * n * d
\end{aligned}
$$

The model of surface roughness parameter $R_{\mathrm{a}}$ is shown in Eqs. 11, 12, and 13, and its measurement coefficients of determination are $\mathrm{R}^{2}=96.5 \%, 96 \%$, and $100 \%$ respectively, and are close to uniform. This means that the revised model can fit the actual data better and can explain the extent to which the model is reliable.

The surface roughness and contour diagram are shown in Figs. 6, 7, and 8, clearly indicating the relationship between each cutting parameter.

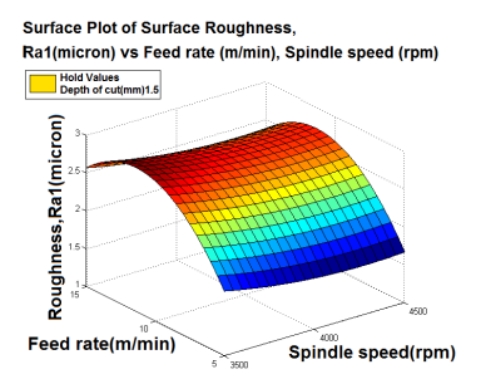

(a) Surface graph of $R_{a} 1$

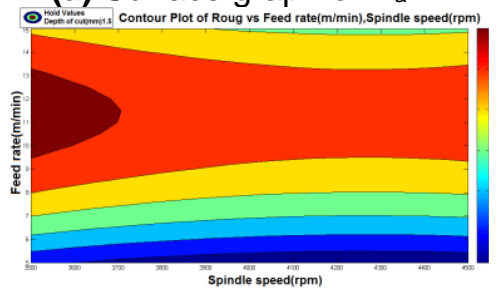

(a') Contour map of $R_{\mathrm{a}} 1$

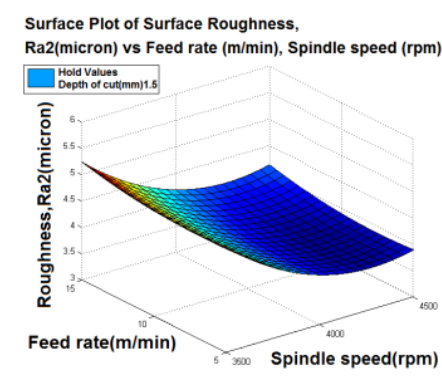

(b) Surface graph of $R_{a} 2$

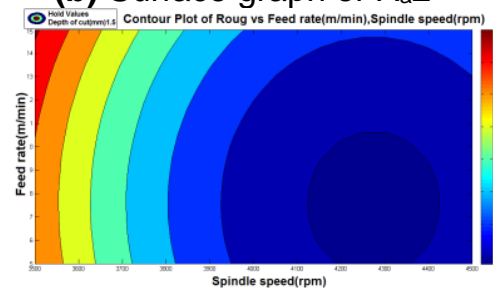

(b') Contour map of $R_{\mathrm{a}} 2$

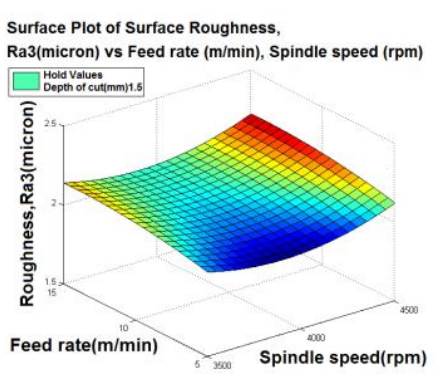

(c) Surface graph of $R_{\mathrm{a}} 3$

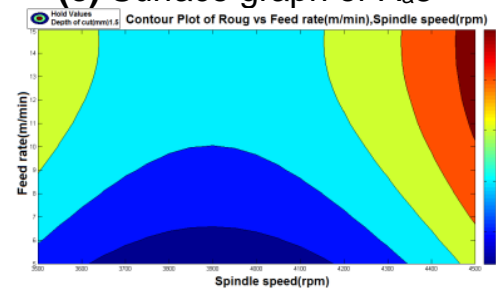

(c') Contour map of $R_{\mathrm{a}} 3$

Fig. 6. Influence of spindle speed and feed speed on surface roughness $(d=1.5 \mathrm{~mm})$

Figure 6 shows the effect of the spindle speed $(n)$ and feed speed $(f)$ on the surface roughness of bamboo with the cutting depth $(d)$ at a medium level $(d=1.5 \mathrm{~mm})$. High spindle speed and low feed speed produces an optimal $R_{\mathrm{a}} 1$, while high spindle speed and low feed speed produces an optimal $R_{\mathrm{a}} 2$. High $R_{\mathrm{a}} 2$ occurred at a low spindle speed and at a high feed speed. The medium spindle speed and low feed speed produces an optimal $R_{\mathrm{a}} 3$ and occurred at a high spindle speed and a high feed speed. The analysis results are the same as above.

Figure 7 shows the effect of spindle speed $(n)$ and cutting depth $(d)$ on the surface roughness of bamboo with the feed speed $(f)$ at an intermediate level $(f=10 \mathrm{~m} / \mathrm{min})$. High spindle speed and low feed speed produces an optimal $R_{\mathrm{a}} 1$. According to Fig. 7(b) and (b'), high spindle speed and high feeding speed produces an optimal $R_{\mathrm{a}} 2$, and a high $R_{\mathrm{a}} 2$ occurred at a low spindle speed and a high feeding speed. It was deduced from Fig. 7 (c) and $\left(c^{\prime}\right)$ that the medium spindle speed and high feeding speed produces an optimal $R_{\mathrm{a}} 3$, and a high $R_{\mathrm{a}} 3$ occurred at a high spindle speed and a low feeding speed. The analysis results are the same as above. 


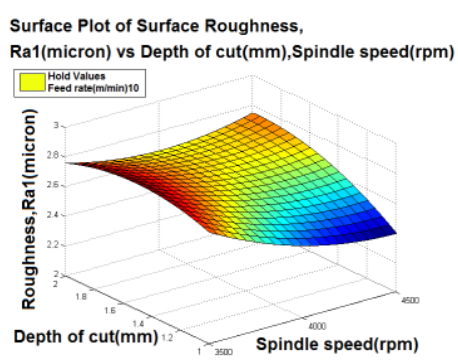

(a) Surface graph of $R_{a} 1$

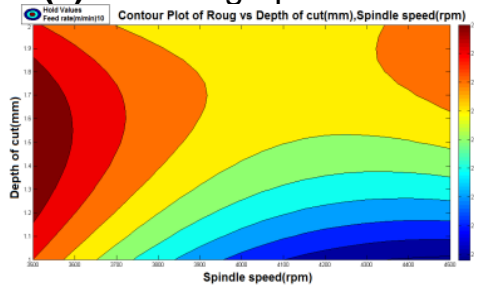

(a') Contour map of $R_{a} 1$

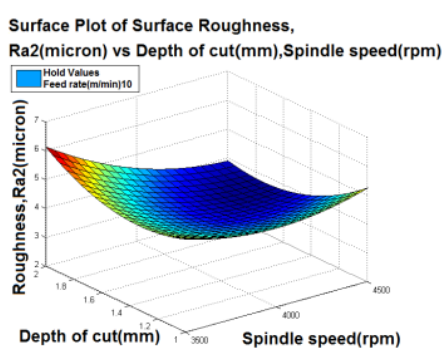

(b) Surface graph of $R_{a} 2$

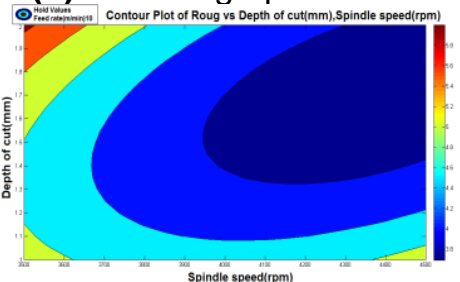

(b') Contour map of $R_{\mathrm{a}} 2$

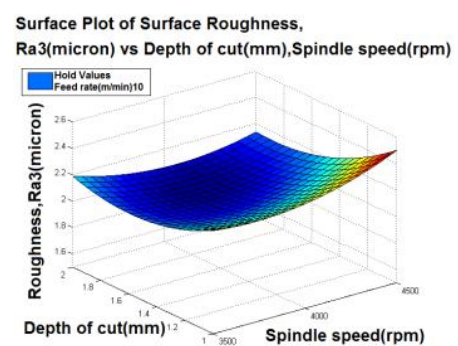

(c) Surface graph of $R_{3} 3$

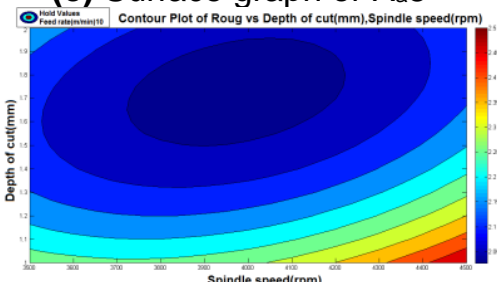

(c') Contour map of $R 3$

Fig. 7. Influence of spindle speed and cutting depth on surface roughness ( $f=10 \mathrm{~m} / \mathrm{min})$

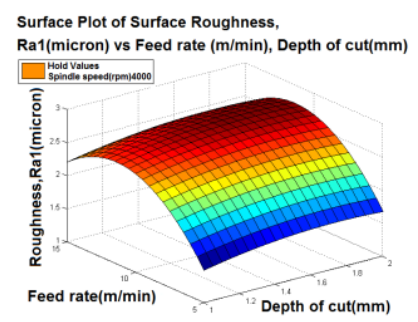

(a) Surface graph of $R_{\mathrm{a}} 1$

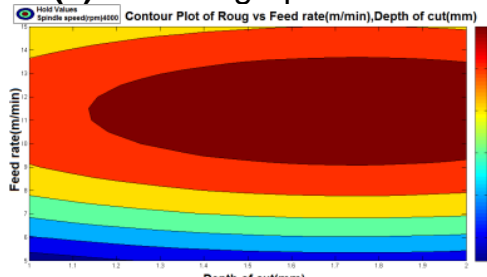

(a') Contour map of $R_{a} 1$

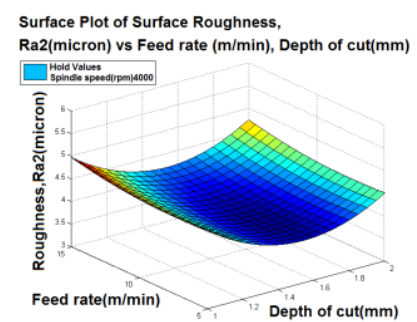

(b) Surface graph of $R_{a} 2$

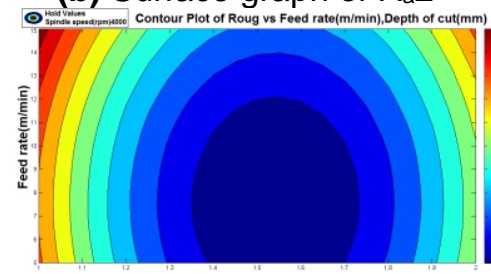

(b') Contour map of $R_{a} 2$

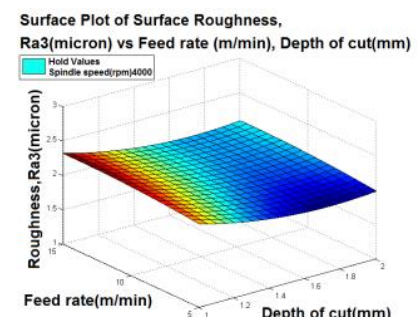

(c) Surface graph of $R_{\mathrm{a}} 3$

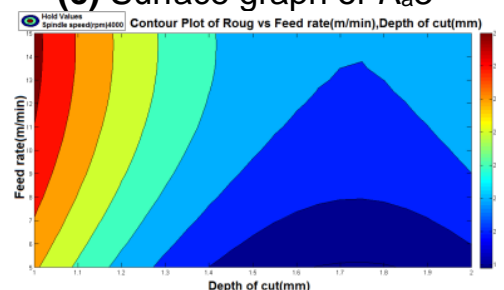

(c') Contour map of $R a 3$

Fig. 8. Influence of feed speed and cutting depth on surface roughness ( $n=4500 \mathrm{rpm}$ )

Figure 8 shows the effect of feed speed $(f)$ and cutting depth $(d)$ on the surface roughness of bamboo with the spindle speed $(n)$ at a medium level $(n=4500 \mathrm{rpm})$. According to Fig. 8 (a) and (a'), low spindle speed and low feed speed produces an optimal $R_{\mathrm{a}} 1$, and a high $R_{\mathrm{a}} 1$ occurred at a high spindle speed and a high feed speed. From Fig. 8 (b) and (b'), the medium spindle speed and low feed speed produces an optimal $R_{\mathrm{a}} 2$ and a high $R_{\mathrm{a}} 2$ that occurred at a place of high feed speed and low spindle speed or high spindle speed. It was deduced from Fig. 8 (c) and (c') that high spindle speed and low feed speed produces an optimal $R_{\mathrm{a}} 3$ and $R_{\mathrm{a}} 3$ occurred at a low spindle speed and a high feed speed. The analysis results are the same as above.

\section{Optimization}

Bamboo also has a wide range of uses such as bamboo flooring, bamboo furniture, etc. When the surface roughness of bamboo corresponds to the minimum value of the mathematical model, it can be considered as the best result, that is, the optimal surface 
quality, using Matlab 2010 software to analyze and to establish the mathematical model of the surface roughness optimal solution as shown in Table 7

Table 7. Optimal Solution for Surface Roughness

\begin{tabular}{|c|c|c|c|c|c|}
\hline & $\begin{array}{c}\text { Spindle } \\
\text { Speed } \\
(\mathrm{rpm})\end{array}$ & $\begin{array}{c}\text { Feed Rate } \\
(\mathrm{m} / \mathrm{min})\end{array}$ & $\begin{array}{c}\text { Cutting } \\
\text { depth }(\mathrm{mm})\end{array}$ & $\begin{array}{c}\text { Min } R_{\mathrm{a}} \\
(\mu \mathrm{m})\end{array}$ & $\begin{array}{c}\text { Max } R_{\mathrm{a}} \\
(\mu \mathrm{m})\end{array}$ \\
\hline $\begin{array}{c}\text { bamboo } \\
\text { tangential section }\end{array}$ & 4500 & 5 & 1 & 1.3937 & - \\
\cline { 2 - 6 } & 3500 & 11.4 & 1.51 & - & 2.8956 \\
\hline $\begin{array}{c}\text { bamboo cross } \\
\text { section }\end{array}$ & 4393 & 7.6 & 1.71 & 3.665 & - \\
\cline { 2 - 6 } $\begin{array}{c}\text { bamboo radial } \\
\text { section }\end{array}$ & 3500 & 15 & 2 & - & 6.3573 \\
\cline { 2 - 6 } & 3974 & 5 & 1.73 & 1.9451 & - \\
\hline
\end{tabular}

The optimal $R_{\mathrm{a}} 1$ was obtained by combining the cutting parameters with the spindle speed of $4500 \mathrm{rpm}$, the feed speed of $5 \mathrm{~m} / \mathrm{min}$, and cutting depth of $1 \mathrm{~mm}$. The maximum value of $R_{\mathrm{a}} 1=2.8956 \mu \mathrm{m}$ was obtained with the combined spindle speed of $3500 \mathrm{rpm}$, feed speed of $11.4 \mathrm{~m} / \mathrm{min}$, and cutting depth of $1.51 \mathrm{~mm}$.

With the combination of cutting parameters, the optimal $R \mathrm{a} 2$ was obtained at a spindle speed of $4393 \mathrm{rpm}$, feed speed of $7.6 \mathrm{~m} / \mathrm{min}$, and cutting depth of $1.71 \mathrm{~mm}$. The maximum bamboo value of $R_{\mathrm{a}} 2=6.3573 \mu \mathrm{m}$ was obtained by combining the spindle speed of $3500 \mathrm{rpm}$, feed speed of $15 \mathrm{~m} / \mathrm{min}$, and cutting depth of $2 \mathrm{~mm}$.

The optimal $R_{\mathrm{a}} 3$ was obtained by combining the cutting parameters with the spindle speed of $3974 \mathrm{rpm}$, feed speed of $5 \mathrm{~m} / \mathrm{min}$, and cutting depth of $1.73 \mathrm{~mm}, R_{\mathrm{a}} 3=1.9451$ $\mu \mathrm{m}$. The maximum $R_{\mathrm{a}} 3=2.5253 \mu \mathrm{m}$ was obtained with the combined spindle speed of $4500 \mathrm{rpm}$, feed speed of $14.5 \mathrm{~m} / \mathrm{min}$, and cutting depth of $1 \mathrm{~mm}$.

\section{CONCLUSION}

1. In this paper, the effect of the three variables: spindle speed, feed speed and cutting depth on the surface roughness of the tangential, cross, and radial sections of bamboo milling is discussed. This experiment adopts orthogonal experimental design. The results show that the order of the effect of cutting parameters on Ra1 is the feed speed, the spindle speed, and the cutting depth. The order of effect of cutting parameters on Ra2 is the spindle speed, the feeding speed, and the cutting depth. The order of the effect of cutting parameters on Ra3 is the cutting depth, the feed speed, and the spindle speed.

2. The main effect diagram of average Ra1 shows that within a specific range, better Ra1can be obtained using $4500 \mathrm{rpm}$ spindle speed, $5 \mathrm{~m} / \mathrm{min}$ feed speed, and $1 \mathrm{~mm}$ cutting depth. The main effect diagram of average $\mathrm{Ra} 2$ shows that, within a specific range, better Ra2 can be obtained using $4500 \mathrm{rpm}$ spindle speed, $5 \mathrm{~m} / \mathrm{min}$ feed speed, and $1 \mathrm{~mm}$ cutting depth. The main effect diagram of Ra3 shows that, within a specific range, better Ra3 can be obtained using a spindle speed of 4000rpm, a feeding speed of $5 \mathrm{~m} / \mathrm{min}$ and a cutting depth of $1.5 \mathrm{~mm}$. The results of the interaction between the surface roughness of the tangential, cross, and radial sections show that there is a relationship between the cutting parameters.

3. The results of variance analysis show that the feed speed has a considerable effect on the surface roughness of the tangential section of the bamboo, the spindle speed has a 
good effect on the surface roughness of the cross-section of the bamboo, and the cutting depth also has a significant effect on the surface roughness of bamboo in the radial section.

4. The regression model of surface roughness is established as follows:

$$
\begin{aligned}
& R_{\mathrm{a}} 1=6.653-0.00348^{*} n+0.584333 * f-0.0867 * d+3.467 * 10^{-7} * n^{2} \\
& -0.02567 * f^{2}-0.3733^{*} d^{2}+0.0003467 * n * d ; \\
& R_{\mathrm{a}} 2=33.6267-0.0138133 * n-0.07367 * f+0.76 * d+2.0133 * 10^{-6} * n^{2} \\
& +0.004867 * f^{2}+2.6933 * d^{2}-0.002267 * n * d ; \\
& R_{\mathrm{a}} 3=7.803-0.00276 * n+0.03383 * f-0.5967 * d+4.067 * 10^{-7} * n^{2} \\
& -0.001167 * f^{2}+0.4867 * d^{2}-0.000273 * n * d ;
\end{aligned}
$$

The analysis using the regression model shows that the fitting degree was close to 1 , which indicates that this is a good method to predict the response and has reliable results for the surface roughness. It can therefore be used to determine the appropriate cutting process to achieve the optimal bamboo surface processing quality. The optimal $R_{\mathrm{a}} 1=$ $1.3937 \mu \mathrm{m}$ can be obtained by employing spindle speed of $4500 \mathrm{rpm}$, a feed speed of $5 \mathrm{~mm}$ /rev and a cutting depth of $1 \mathrm{~mm}$. The optimal $R_{\mathrm{a}} 2=3.665 \mu \mathrm{m}$ can be obtained using the cutting parameters of a spindle speed of $4393 \mathrm{rpm}$, a feed speed of $7.6 \mathrm{~mm} / \mathrm{rev}$ and a cutting depth of $1.71 \mathrm{~mm}$. The optimal $R_{\mathrm{a}} 3=1.9451 \mu \mathrm{m}$ can be obtained by combining the cutting parameters of spindle speed of $3974 \mathrm{rpm}$, a feed speed of $5 \mathrm{~m} / \mathrm{min}$ and a cutting depth of $1.73 \mathrm{~mm}$.

\section{ACKNOWLEDGMENTS}

The authors are grateful for the financial support from the Basic Research Fund of the Chinese Academy of Forestry (Grant No. CAFYBB2017QB008), Basic Research Fund of the Chinese Academy of Forestry (Grant No. CAFYBB2017ZC008) and National key research and development program of the 13th five-year plan (Grant No. 2017YFD060080104).

\section{REFERENCES CITED}

Çelik, Y. H., Kilickap, E., and Güney, M. (2016). "Investigation of cutting parameters affecting on tool wear and surface roughness in dry turning of Ti-6Al-4V using CVD and PVD coated tools," Journal of the Brazilian Society of Mechanical Sciences and Engineering 39(6), 2085-2093. DOI: 10.1007/s40430-016-0607-6

Debnath, S., Reddy, M. M., and Yi, Q. S. (2016). "Influence of cutting fluid conditions and cutting parameters on surface roughness and tool wear in turning process using Taguchi method," Measurement 78, 111-119. DOI:

10.1016/j.measurement.2015.09.011

Goli, G., Curti, R., Marcon, B., Scippa, A., Campatelli, G., Furferi, R., and Denaud, L. (2018). "Specific cutting forces of isotropic and orthotropic engineered wood products by round shape machining," Materials 11, 2575.

Guo, Y. J. (2009). Effects of Milling Parameters for Bamboo on its Milling Qualities and Unit Cutting Work, Beijing Forestry University, Beijing, China.

Hanafi, I., Khamlichi, A., Cabrera, F. M., Almansa, E., and Jabbouri, A. (2012).

"Optimization of cutting conditions for sustainable machining of PEEK-CF30 using 
TiN tools," Journal of Cleaner Production 33, 1-9. DOI:

10.1016/j.jclepro.2012.05.005

Kamboj, G., Gašparík, M., Gaff, M., Kačík, F., Sethy, A. K., Corleto, R., Razaei, F., Ditommaso, G., Sikora, A., Kaplan, L., et al. (2020). "Surface quality and cutting power requirement after edge milling of thermally modified meranti (Shorea spp.) wood," Journal of Building Engineering 101213. DOI: 10.1016/j.jobe.2020.101213

Li, W., and Zhang, Z. (2019). "Effect of cutting tool with micro-pits texture on wood cutting performance," PLOS One 14(4), e0214888. DOI: 10.1371/journal.pone.0214888

Saini, S., Ahuja, I. S., and Sharma, V. S. (2012). "Influence of cutting parameters on tool wear and surface roughness in hard turning of AISI H11 tool steel using ceramic tools," International Journal of Precision Engineering and Manufacturing 13(8), 1295-1302. DOI: 10.1007/s12541-012-0172-6

Sarıkaya, M., and Güllü, A. (2014). "Taguchi design and response surface methodology based analysis of machining parameters in CNC turning under MQL," Journal of Cleaner Production 65, 604-616. DOI: 10.1016/j.jclepro.2013.08.040

Stanojevic, D., Mandic, M., Danon, G., and Svrzic, S. (2017). "Prediction of the surface roughness of wood for machining," Journal of Forestry Research 28(6), 1281-1283. DOI: $10.1007 / \mathrm{s} 11676-017-0401-\mathrm{z}$

Tiryaki, S., Özşahin, Ş., and Aydın, A. (2016). "Employing artificial neural networks for minimizing surface roughness and power consumption in abrasive machining of wood," European Journal of Wood and Wood Products 75(3), 347-358. DOI: 10.1007/s00107-016-1050-1

Wu, L. Q. (2006). Study on the Cutting Performance of Bamboo, Beijing Forestry University, Beijing, China

Xiao, Z., Liao, X., Long, Z., and Li, M. (2016). "Effect of cutting parameters on surface roughness using orthogonal array in hard turning of AISI 1045 steel with YT5 tool," The International Journal of Advanced Manufacturing Technology 93(1-4), 273282. DOI: $10.1007 / \mathrm{s} 00170-016-8933-5$

Yan, J., and Li, L. (2013). "Multi-objective optimization of milling parameters - the trade-offs between energy, production rate and cutting quality," Journal of Cleaner Production 52, 462-471. DOI: 10.1016/j.jclepro.2013.02.030

Article submitted: July 7, 2020; Peer review completed: August 23, 2020; Revisions accepted: September 10, 2020; Published: September 16, 2020.

DOI: 10.15376/biores.15.4.8323-8338

Erratum: September 22, 2020: Feed rate units were changed from $\mathrm{mm} / \mathrm{rev}$ to $\mathrm{m} / \mathrm{min}$ 